\title{
1
}

\section{Introduction: Suitability Issues in Mass Appraisal Methodology}

\author{
Tom Kauko and Maurizio d'Amato
}

Note: In Italian academia, the system of output registration requires jointly published articles to include an indication of the parts written by each author. Although the work was carried out in strict cooperation between the two authors, we may approximate that most of the second, third, fourth and fifth sections were written by Tom Kauko while most of the first, sixth and seventh sections were written by Maurizio d'Amato.

\section{Background}

Currently, quantitative methods in social and economic sciences are undergoing a renaissance; after at least three decades of being dubbed boring and stale, the methods have resurged into the mainstream again. This is particularly true for spatial sciences and human geography. A variety of reasons for this can be noted: an improvement in computing technology, better data registers and availability, and the launch of end-user friendly software. One more specific reason is the need to standardize the procedures of property valuation and mass appraisal. This is a consequence of economic globalization - today a homogenous valuation/appraisal method is required all over the world. The International Accounting Standards/International Financial Reporting Standard (IAS/IFRS) and the International Valuation Standard (IVS) address this important issue. Because of the expansion of business activity across national borders it is becoming increasingly indispensable to propagate consistent approaches to the valuation of real estate for accounting, banking activity, stock exchange (bourse) listing and secured lending purposes (Mansfield and Lorenz, 2004). This is articulated in the Guidance Note n. 13 of IVS (I.V.S.C., 2005) 1.7 as follows: 'The Development 
of Mass Appraisal Systems for property taxation should follow recognized scientific standards in statistical applications...', which in turn has led to particular emphasis being given to a multiple regression analysis (MRA) approach.

On top of the scientific and business motivations above, one can also find some planning and policy relevant grounds for the use of empirical modelling techniques and automated valuation methods (AVM). It is widely recognized today that the development of urban areas requires sustainability. It is also increasingly being recognized that this concept is multi-dimensional, involving ecological, environmental, economic, social and cultural aspects such as viability and quality-of-life (QOL). With the help of mass appraisal methods it is possible to extract key dimensions of viability and QOL from a complex set of micro-level housing market data. This requires the use of high quality data cross-sections and a robust modelling tool. This could be characterized as an innovative socio-economic and geographic approach to the analysis of markets and price formation - the methodology is quantitative by definition, but because of the practical applicability aspect involved, it is not restricted to elegant formal modelling protocols. Currently, however, comprehensive mass appraisal systems - possibly involving AVMs - are limited to property tax applications in a few countries, notably the USA and Denmark. We also anticipate, in line with de Soto (2000) that an AVM can play different roles in different economies, in which case formal or non formal economies with stronger or weaker institutions require different approaches to mass appraisal methodology.

Mass appraisal may be defined as a systematic appraisal of groups of properties using standardized procedures. Mass appraisal methods normally refer to large groups of properties rather than to a single property. The accurate assessment of the value of a predefined set of properties - or one particular property - indirectly, using a model, for a given practical purpose, is the main target of these methods (e.g., McCluskey et al., 1997; González et al., 2002a,b). Several contributions have addressed the importance of mass appraisal, exploring the relationship between the property value, the property characteristics and urban social and economic problems. The market behaviour is influenced by the property prices, the high durability of the property asset and by the fixed geographic location (Robinson, 1979; Harvey, 1996). Hedonic price modelling has been proposed to define an econometric relationship between the price and the property characteristics, particularly in a residential context. Arguably, the standard MRA-based hedonic price models may not be suitable for capturing all the necessary information involved in the value formation process, and the literature on how to develop the value modelling tools further is (or at least should be) evolving. On the other hand, there are property markets where data are not available or, even if such data are available, it may not be organized into a property data bank. 
In this case other kinds of AVMs with a less deterministic relation between property value and property attributes may help. Although the problems are highlighted, at the moment MRA remains the most important theoretical framework in mass appraisal.

The quantitative, MRA-based methodology may be referred to as the 'orthodox' approach to mass appraisal valuation. Several methods have been applied in the last decade defining a new approach to property mass appraisal valuation. In this work, these methods and methodologies are dubbed 'heretic' because of their different theoretical basis from the MRA, the dominant approach to mass appraisal. Model-free estimation techniques, such as neural networks and fuzzy logic, have been introduced to bring some flexibility to the property value calculations, without neglecting the mathematical rigour. In doing so, the value model becomes more powerful than its formal, regression-based and completely crisp counterpart. Pattern recognition is yet another relatively untried approach within this realm. Indeed a number of contributions here offer ingenious and pragmatic, if not totally transparent, modelling methodology (see e.g., Jenkins et al., 1999; McCluskey and Anand, 1999).

In this book we set out to explore the possibilities within this undertheorized problem area. We explore the possibilities for developing mass appraisal methods following two different arguments: one, that the performance and feasibility of appraisal methods may be compared and evaluated with regard to a set of technical criteria; and two, that differences in the suitability of methods also have to do with the particular context where application takes place. Our objectives are first, to understand the problem of advancing mass appraisal methods/expertise from two different points of view: the scientific debate and practical feasibility; second, to evaluate a set of methods based on a set of specific criteria, partly technical/practical and partly institutional; and third, to establish an international platform for broader networking.

\section{Orthodox approaches to mass appraisal valuation}

Two related modelling traditions exist today, both of which deploy MRA for estimation: the model driven hedonic approach, and the data driven statistical approach. Hedonic price models comprise the most frequently applied models in the valuation practice as well as in monitoring the housing market. In these models the variables are usually of two basic types: internal physical (i.e., house and plot specific, structural) and external locational. On top of that there may be additional variables, most notably some type of inflation control (e.g., Miller, 1982). The purpose of the development of the hedonic price model was to make possible econometric analysis 
of large databases of price and other recorded information describing the nature of the property and its vicinity, and possibly some specific (other) circumstances of the transaction. A more practical or a theoretical statistical approach, especially the regression analysis-based value/price-modelling tradition, has been applied in order to provide tools for valuation conducted by the public and private sectors in many countries with convenient land information infrastructure (i.e., readily available digital register information with the possibility of multiple spatial aggregation).

There are several MRA-based house price studies that are made either with or without the formal hedonic price theory underpinnings. As shown by a multitude of studies (see e.g., reviews by Ball, 1973; and Lentz and Wang, 1998) the measures of success have been the model fit (indicated by the total correlation coefficient, the $R$-squared statistic), the model significance (the $F$-test at a given level of significance), whether each independent variable has the anticipated sign of price association (indicated by the partial correlation coefficients) and whether each independent variable is statistically significant (indicated by the $t$-statistic and a given risk percentage level). The standard error of the model and various test statistics are also applied as formal criteria of modelling performance. Recently, hedonic modelling has been applied successfully for constant-quality price indices (Hoesli et al., 1997a); determining rental values (Hoesli et al., 1997b); estimating the disturbance effect of traffic (Wilhelmsson, 2000); and estimating implicit prices (Laakso, 1997).

In the empirical hedonic modelling literature locational proxy variables may be defined in various ways (cf. surveys by Ball, 1973; Miller, 1982; Laakso, 1997; Lentz and Wang, 1998; see also Thériault et al., 2005, for sophisticated accessibility measures). Kang and Reichert (1991) constructed a locational quality dummy based on levels of price per $\mathrm{m}^{2}$ living space. Similarly, McCluskey and Anand (1999) used a solution where the location was captured with a seven-valued categorical 'ward'-variable, with values based on mean transaction prices for that area.

Adding location to the already complex analysis of residential differentiation has become easier with the help of modern geographic information systems (GIS). There are obviously operational problems with the hedonic model, such as lack of suitable variables and data, and the issue of spatial resolution, that is choosing a wrong level of spatial aggregation. This brings us towards GIS-aided analysis, with the benefit of data visualization and storage, the possibility to construct more efficient accessibility measures and spatial analysis. An additional point is that the GIS-technology makes valuemodelling applications more user-friendly. For GIS-demonstrations within property valuation, see Orford (1999); Rodriguez and colleagues (1995); Wyatt (1995, 1996a,b, 1997); Lake and colleagues (1998); and Ding and colleagues (2000). See also Bible and Hsieh (1996) for analysis of apartment rents 
Furthermore, a GIS also helps in correcting the spatial discontinuity problem when the spatial dimension is incorporated in the analysis more explicitly than in the standard hedonic model (Orford, 1999, pp. 63-67; see also Wyatt, 1995, 1996a,b).

In a GIS only a few spatial statistical methods can be integrated. When the spatial analysis system is 'loosely coupled', the statistical analyses are performed separately from the GIS interface. Both packages thus have their own function in the system: the raw data are transported to a GIS for storage, visualization and generation of variables for analysis of locational externalities, most notably proximity indicators. Then, the latter may be exported to a separate statistical package where, for instance, standard regression analysis or more sophisticated multi-level regression analysis (see below) may be undertaken. Finally, the analysed data may be imported to the GIS again, for storing and visualizing. Then, the output of a GIS becomes a surface indicating the spatial effect of a given variable on price. Studies by Orford (1999); Lake and colleagues (1998), Rodriguez and colleagues (1995) and Bible and Hsieh (1996) manage to show that, in one way or another, the importance of location is great (see also Wyatt, 1996a,b, 1997). In general, the GIS-aided property value analysis is feasibly linked to broader register information (Federal land cadastre of Russia, 2001).

Today a variety of advanced spatial techniques enhance the possibilities of handling location in the hedonic-based house price analysis. Namely, the consideration of sub-markets and spatial drift may improve results substantially (see Orford, 1999). This requires an appropriate routine of handling the non-linearity and dynamics prevailing across space. State-of-the-art methods include multi-level specifications and spatial expansion models. Kriging is an advanced spatial statistical method that builds on parametric MRA. When the standard hedonic MRA principle is $\Sigma X_{m} \Rightarrow Y_{m}$, the kriging principle is $\Sigma Y_{n} \Rightarrow Y_{m}$ (e.g., Chica Olmo, 2007).

In multi-level specifications, each externality effect is measured at an appropriate level. In order to add some efficiency into the (hedonic) value model, the variation in house prices is decomposed between different spatial scales. In the case of property valuation applications, the appropriate levels may be neighbourhood, street and property levels. A major advantage of this specification is the ability to differentiate between compositional and contextual effects of location on house prices, in other words of spatial variations in the housing stock and the place itself (Orford, 1999, 2002).

In the spatial expansion model, the contribution of a housing characteristic to the price is allowed to change over space. This reflects a series of interrelated sub-markets with sliding boundaries. Many applications use such a specification where parameters vary in order to cope with the spatial heterogeneity of a housing market (e.g., Geoghegan et al., 1997; see also Wilhelmsson, 2002). 
We can note related contributions: Gillen and colleagues (2001) discuss autocorrelation when it is either a function of distance separating properties in space (isotropic) or a function of distance and direction (anisotropic). Riddel (2001) improves the hedonic approach by allowing for interaction between space and time in a dynamic modelling framework, as environmental quality may induce market disequilibria. Hierarchical trend modelling, with hedonic underpinnings using a Kalman filter, has been proposed by Francke and Vos (2004).

In many situations exogenous factors or lack of information constrain individuals to participate in segments of a larger market (Michaels and Smith, 1990). However, standard hedonic analysis has not ignored market segmentation completely (Simonotti, 1998; Salvo, 1999). In principle, a hedonic regression cannot detect zonal boundaries, only the significance of the direction and coefficient of the effect of the value factors, as well as the accuracy and explanatory power within the total sample of observations. One way of clarifying the issue is to use dummy variables (Laakso, 1997). Another solution is to calculate hedonic quality ranks for each observation (Rothenberg et al., 1991, pp. 380-385). A third option is to construct separate models for separate subsets of the data, with each subset, usually comprising all transactions within a region, having its specific hedonic equation (i.e., the partitioning approach). Hence the data are split into different segments, which are either a priori predefined or somehow synthesized. Also, if segmentation in a theoretical sense is ignored, the partitioning approach may be justified (see Needham et al., 1998).

Demand side segmentation, that is, collective preferences according to membership of an a priori defined ethnic or socio-economic group, is often studied with the specified two stage procedures of hedonic modelling. If the functional form is curvilinear we may derive willingness to pay (WTP)/willingness to accept (WTA) estimates based on the shadow prices and specified demand side data. (If the equation is linear, the second step in the two-step hedonic approach cannot be taken.) The targets then are the marginal WTP estimates (i.e., demand functions) for each relevant characteristic by groups (e.g., Bökemann and Feilmayr, 1997).

Integration between the adjustment grid methods and regression analysis was developed by Colwell, Cannaday and $\mathrm{Wu}$ (1983, cited in Kang and Reichert, 1991), in order to integrate the ordinary least squares (OLS) estimation of adjustment factors to the standard method. Here the multiplicative percentage grid adjustment method is considered a particularly promising option according to Kang and Reichert (1991). Another example of earlier innovations is the Stein rule (Knight et al., 1993). Here, the idea is to improve the estimation accuracy by the following procedure: first add all variables to the model and estimate the partial correlations (i.e., beta coefficient, marginal adjustment factors) with OLS. Then, remove the variables for which it is believed that beta equals zero, in other words the 
insignificant effects on price, and estimate a new beta with a restricted regression. After that the estimates are compared. According to the Stein rule, if the coefficients are close to each other, then the beta estimated with the restricted regression obtains a greater weight, and the more the results differ, the smaller the weight for the restricted beta estimates. The result is then a product of both the data and the relevant domain knowledge of the appraiser.

Logistic regression (i.e., regression where the dependent variable is a dummy; discrete choice) is not so common within the value-modelling field (Feenberg and Mills, 1980, p. 110). In a rare study, Bolen and colleagues (1999) used logistic regression to estimate probabilities of land value increases and residential rent increases related to certain characteristics in Istanbul. They justified the use of the method by the irregularity of the urban system.

\section{In between orthodoxy and heresy - model-free regression}

Flexible (i.e., model-free) regression methods are considered an interesting research methodology within the formal modelling paradigm too. More generally, Verkooijen (1996) used the term 'flexible regression' rather than 'non'- (or 'semi'-) parametric regression, for:

- Local approximations $\mathrm{E}[Y \mid X=x]$ (e.g., locally weighted regression such as splines or kernel).

- Low dimensional expansions $f(x)=\sum \varnothing_{i} z_{i}$ (e.g., additive models, with both parametric and non-parametric components).

- Adaptive computation (e.g., neural networks, see next section).

In the context of estimating house prices or property values, flexible regression has been discussed and encouraged by Meese and Wallace (1991); Pace (1995); Mason and Quigley (1996); Verkooijen (1996); and Kyllönen and Räty (2000) to name some recent studies. Coleman and Larsen (1991), in turn, remain more critical towards alternative estimation techniques. Furthermore, a number of contributions apply this approach for the explicitly spatial dimension. Pavlov's (2000) space-varying coefficients not only combine the two main spatial methods (the error method and drift/lagged method), but also manage to incorporate location as a non-parametric influence without any inferential theory underpinnings. The spline approach was used by Dubin and Sung (1987), who used a linear, an exponential and a quadratic approximation for the rent gradient, measured through 'rays' drawn from the city centre, each of them capturing the price-distance relationship in one significant direction.

According to Mason and Quigley (1996), theory does not provide guidance about the choice of functional form; thus this is purely an empirical 
matter. For this goal, non-parametric (and semi-parametric) methods offer advantages in relation to confirming non-linear relationships. The generalized additive model (GAM) proposed by Mason and Quigley is based on an arbitrary smoother of the curvature. It is a compromise between the generality of methods such as kernel or local regression, and the comprehensibility of the parametric MRA. Its benefit is the tractability of the results, but it comes at the cost of suppression of complexity.

In a very similar vein, Colwell (1998) and subsequently Colwell and Munneke (2003) apply an interesting approach for estimating price surfaces of urban land within a non-parametric regression approach. The shape of the spatial price surface cannot be assumed to be of any particular form hence, non-parametric estimation. The particular method, referred to as piecewise parabolic multiple regression analysis (PPMRA), assumes straight lines between valleys and peaks, and full continuity. The space is divided into discrete, but contiguous, square spatial units. The resulting function is a continuous, but less than totally smooth (i.e., not everywhere differentiable) spline function. As independent variables, Colwell and Munneke apply barycentric coordinates - a standardization and weighted average procedure that transforms the absolute values into relative ones, to add to the efficiency of the method. The regression coefficients of these coordinates reflect the vertex relative to the constant term. They also note a trade-off between a gain of continuity and a loss of degrees of freedom. On balance, their work is innovative and offers an adequately valid tool for general property market analysis, as well as mass appraisal purposes (feasibility criteria notwithstanding). A particular advantage is the ability to avoid the problem of too-smoothed point estimates that mar the analysis of most semiparametric methods. This shows the advantage of the piecewise method: it generates a true surface output and not just a matrix of points. A balancing aspect in the comparison is, however, the problem that the lines between the vertices in piecewise regression are straight lines (thus, the curve is not differentiable, although continuous), which in turn suggests that the method is not so flexible in this respect.

Finally, a few words on the assumptions they use: they note that (1) market discontinuities caused by topography and government policy are destroyed by arbitrage, which we really consider true for time-series only, not space; and that (2) if such discontinuity persists, this can easily be modelled. This bold 'guarantee' is of course still within the belief of neoclassical modelling rationality and tractability; personally, we really do not believe in this as a categorical assumption, as land markets are not continuous in space. Thus, we have spotted a problem with the method - it uses after all fairly rigid orthodox underpinnings. This point is worth reiterating: while standard housing models and urban/land economics models do not allow for discontinuities and non-linearities very well, it seems reasonable to assume 
that time has a linear price association, whereas space/segmentation has a non-linear relation (e.g., due to regulation, perceptions of individuals or topography).

Páez and colleagues (2002) deal with geographically weighted kernel models that allow for locational heterogeneity. Geographically weighted regression (GWR, Fotheringham) is growing in popularity among geographers and real estate market modellers. It is considered a locally weighted regression method that operates by assigning weights to all observations depending on their distances to a geographical focal point (Páez et al., 2002). The idea is to run a separate regression for each observation point, and, using $X, Y$ identification of the observations, produce a surface of response functions. Thus, GWR generates different coefficients for each point in the data set, and subsequently the responses for each $X, Y$ point can then be computed based on the input (either the actual indicator values of the observations or their mean values).

Flexible estimation is carried out in order to estimate the distribution itself from the data. While flexible estimation is an alternative to that of fixed parametric, an inevitable trade-off makes the decision of modelling choice less straightforward: flexible regression is less efficient than fixed parametric regression, but avoids model specification problems - the problem of parametric methods.

\section{Heresy in mass appraisal and valuation - a variety of approaches}

A methodology is here defined as 'heretic' because of the contrast with the dominant framework of multiple regression analysis. These techniques have been developed in several fields. Their application represents an experimental and state-of-the-art benchmark in research activity on mass appraisal. While the evolution of the paradigm is different, and to some extent the philosophy of science position and professional jargon too, we note a partial overlap with the approaches discussed in the previous section.

(Artificial) neural networks (ANN) are a sort of flexible, model-free regression (cf. Verkooijen, 1996; Pace, 1995; see also McCluskey and Anand, 1999). The nature of the neural network is a 'black box', which means that there is no clear functional relationship between the input and output values. The algorithm learns by training. The basic elements in a neural network are called neurons or nodes. The connections between them are determined by weights. Together the neurons process direct inputs, or inputs from other neurons, to give an output value. The inputs must be numerical values. Then the output values are corrected iteratively, until the system has achieved the desired accuracy. There are three basic types of algorithms, the feed-forward, 
feedback and competitive networks, the feed-forward being the most common one. The multi-layer perceptron (MLP) feed-forward network bears a resemblance to multiple regression, except it has no explicit mathematical relationship between the input and output (but see White, 1989). In general, ANNs have proved rather successful for classification in finance and economics, in a similar sense as more established statistical methods such as logistic regression and linear discriminant analysis (Verkooijen, 1996, pp. 97-98). However, during the 1990s, several authors found serious problems with the ANN (e.g., Worzala et al., 1995), which led to an abandonment of this technique from mass appraisal. Nonetheless, Nguyen and Cripps (2001) showed how this technique is efficient for large heterogeneous data samples (we come back to this study below).

The self-organizing map (SOM, Kohonen map), a particular type of ANN, produces a 'feature map' of clusters, each of which is represented as a specific characteristic combination of attribute levels. As a result of the analysis, the researcher obtains a surface where the areas with similar combinations of variables can be looked at as a whole and, on the other hand, compared with different combinations of variables. It is also possible to interpret a 'typical value' of each node, for a given feature. The SOM, being a particularly visual approach, has the advantage that it allows for some qualitative, on top of quantitative, analysis.

Plenty of similarities can be noted between the SOM and the flexible regression methods described above - for example, Colwell and Munneke (2003) compare their PPMRA method with kernel estimation, another flexible regression technique, which is closely related to the SOM. Thus, these methods are also subject to much of the same criticism. However, a few differences are worth noting. One notable difference is that, whereas the kernel (and the SOM) imposes an a priori grid-iron structure on the surface, it inevitably 'smoothens' particularly high and low values (i.e., irons the valleys and peaks), the piecewise parabolic method uses the peaks and valleys as vertices of the grid. Obviously, with the SOM this can be corrected by enlarging the dimensions of the map, so that a sufficiently large resolution allows the peaks and valleys to be fitted with the response.

Several papers have been written on this topic since the early 1990s (e.g., Tay and Ho, 1992; Borst, 1995; Worzala et al., 1995; and McGreal et al., 1998). Some are for and others against the use of ANN for valuation - mainly due to the 'lack of robustness' argument. Nguyen and Cripps (2001) add to the long list of performance comparisons between MLP (back propagation-ANN) and MRA. For an accuracy indicator they use the mean absolute percentage error of the model (i.e., the internal accuracy of the estimated model), and the forecasting error when thresholds of $5 \%$ and $15 \%$ are used (i.e., how large a percentage of the test cases are predicted within percentage $(P \%)$ of the actual sale), when measured with validation samples. They conclude that 
the performance of the MRA model improves when the functional specification improves, whereas the performance of the MLP model improves when the data set used for training increases. Thus, the MRA performs better when small samples are used, but if there is sufficient data size and appropriate network parameters are found, the MLP performs better. When we compare to a similar comparison between the SOM and MRA (Kauko and Peltomaa, 1998; Kauko, 2002), the conclusions were the opposite to these: the ANN-based model performed better than the MRA models for small data sizes in recognizing a hypothesized impact between externality and price. On the other hand, González and colleagues (2002a, 2005) found that for the accuracy performance, ANN is slightly better than MRA and other models. Some of these problems are the same for both ANN-types, the SOM and the MLP: how to set the field ranges of the input variables, when we do not want one factor to dominate too much; when to stop the run based on trial and error, and how to know whether we at that stage have found the optimum; how many variables is optimal to include; and how to explain the 'black box'?

Some further thoughts concerning the similarities between the GWR and SOM techniques can now be put forward. Both are based on models where proximity and intensity determines the response, and the output is heterogeneous as it applies for any point in the data (GWR) or any cluster of points in the data (SOM). The crucial difference is that in GWR models this influence is in geographical $X, Y$ space and in the SOM, it is in the $n$-dimensional space defined by the input variables. In principle this means that if the SOM includes $X$ and $Y$ among the input, and these two variables are given infinite weight - thus in practice sufficiently strong weight compared to the other variables - or if the input is restricted to only these two variables $(X$ and $Y)$, the output looks like the output of GWR. Therefore, if the SOM generates an output where each point corresponds with one single observation, then it should correspond with GWR. However, whether the outcome is exactly the same depends on the definitions of response function and, in the case of SOM, also on the initial values.

The genetic algorithm is another recent semi-parametric tool from the machine-learning paradigm. According to some experts (e.g., J.H. Holland and D.E. Goldberg, cited in Cooley et al., 1994, p. 182), genetic algorithms have proved successful in applications involving the efficient investigation of large search spaces. The genetic algorithm performs an artificial 'breeding' of a replacement population from a randomly generated population of previous encoding, from 'parents' to 'offspring' (see also Cooley et al., 1994).

McCluskey and Anand (1999) highlighted a number of issues within the mass appraisal realm related to functionality and accuracy of value modelling approaches. They also built an intelligent hybrid system, where the neural networks and genetic algorithms were used in association with a 
nearest-neighbour algorithm, a technique applied in classification and pattern recognition. The application involved a distance metrics (Euclidean or significant mean) for determining the similarity between the comparables for nine attributes. Soibelman and González (2002), as well as González and colleagues (2002a,b, 2005), maintain that data-mining analysis - using various techniques - is helpful in its search for unknown patterns. The most important thing, however, is to note that these techniques are only as good as the data you feed them.

Some discussion has been devoted to the issue of whether a more qualitative technique of computerized data processing would after all be better suited to dealing with a complex field such as property valuation (e.g., O'Roarty et al., 1997; McCluskey and Anand, 1999). Rule-based expert systems emerged as a counter paradigm to neural networks and other numerical techniques. This technology models human judgement and decision making by explicit rules, as opposed to learning automatically from historic information. Therein also lies their biggest drawback: intensive expert interviewing takes much time and money (Verkooijen, 1996, pp. 97-98). The problem is that the model designer has to formalize everything, which is rather clumsy, and, if the optimal decision has to be determined based on a data mapping, even misleading. In other words, they do not offer robust solutions. Nevertheless, expert systems have their applicability. Scott and Gronow (1990) discussed the components of valuation expertise within the mortgage valuation domain and further explored the different levels at which this expertise is exhibited. Finally, they suggested the production of an expert system which would reproduce the expertise of the human valuer. McCluskey and Anand (1999), in turn, considered knowledge elicitation and simulation of expertise as strengths, but the lack of robustness and rigidity of models as weaknesses.

Case-based reasoning deals with retrieval of past cases similar to the one to be assessed. Within property valuation this means being based on historical transactions. It does not encapsulate heuristic knowledge, while the selection of variables relies on the data. The method utilizes a case library, formed from comparable evidence, and the most useful of this information held can be retrieved to form an opinion about the value (see Gonzalez and Laureano-Ortiz, 1992; O'Roarty et al., 1997; Bonissone et al., 1998). O'Roarty et al. (1997) stressed, among other things, the flexibility of the system in retrieving cases, rather than merely searching for cases that exactly replicate the input problem cases. Case-based reasoning is, according to Wyatt (1999) the most promising of the new techniques/methods, because it avoids problems in knowledge acquisition. Reasoning from past cases, objectivity and explainability are the main strengths of this method. It negates many of the problems associated with expert systems. However, it requires considerable data (McCluskey and Anand, 1999; see also Pacharavanich et al., 2000). 
Fuzzy logic deals with the 'imprecision of the present' as opposed to probability which deals with the 'uncertainty of the future'. The theory of fuzzy logic is formally specified as a measure for the degree of membership for an element's belonging to a set. These gradations can sometimes be used in property valuation as well (see Bagnoli and Smith, 1998). This is about computing with words. The fuzziness reflects the way of evaluating alternatives and making decisions. Lee and colleagues (2003) argue that fuzzy quantification theory can reduce the subjectivity caused by the appraiser and also allow for a flexible adjustment of effecting factors. For preparation of the more discrete variables they propose a fuzzy linguistic method. By replacing crisp memberships, that is, absolute values of predictor variables, with membership functions that allow for imprecision, the basis for the valuation is improved, they argue. Sui (1992) noted that the problem with conventional crisp methods is the loss of information when faced with ambiguity and imprecision. At the extremes, however, both the fuzzy and crisp type of applications yield the same results. According to Sui, the approach based on fuzzy set theory has its problems too: the difficulty is how to define the correct membership function for spatial purposes, as the membership function is derived ad hoc.

Rough set theory (RST) derives Boolean rules from actual market data, and not expert knowledge (see d'Amato, 2002, 2003, 2007). Furthermore, RST is surely more transparent than ANN. It is also more qualitative than any ANNs (which we find a strength), which of course does not contradict the fact that having more observations to model the rules with would be better here too.

Hybrid systems may be created based on various kinds of artificial intelligence (AI). Pagourtzi and Assimakopoulos (2003) utilized several of the methods discussed. González and colleagues (2002b) built a mass appraisal model where fuzzy rules were extracted from the ANN. The aim of the rules was to explain the computations in the valuation process. These would be understood as kinds of hedonic coefficients. They concluded that, while more testing was needed, the approach was promising (see also d'Amato and Siniak, 2003).

\section{Methods based on interviews and surveys}

Some recent comments freely encourage the use of interview survey methodology for residential valuation. According to Lentz and Wang (1998), to simply ask individuals about their willingness to pay for certain property characteristics, for instance aesthetic value, is an intuitively appealing technique. However, Lentz and Wang (1998) noted that a successful application of the survey method depends on the existence of an informed populace with 
market experience regarding the attributes in question. In the following, we discuss some of the approaches that use judgmental data, from the most common to the most controversial (but state-of-the-art) ones.

The contingent valuation method $(\mathrm{CV})$ is based on a formal questionnaire about the respondent's WTP or - in reverse situations - his/her WTA a given sum of money (see Breffle et al., 1998; Ruokolainen and Tempelmans Plat, 1998; Ruokolainen, 1999). Estimates generated by CV and hedonic modelling have been compared in several contexts (see e.g., Willis and Garrod, 1993; Wilhelmsson, 2000). Usually, the hedonic method is considered more reliable, because the analysis is based on actual rather than hypothetical data. The sensitivity to the rate of discount might prove another problem with contingency valuation if monthly and total expenditures have to be compared (e.g., Vainio, 1995). However, in some cases the prices paid do not reflect all the possible externalities, as they become familiar only with time. For instance, in Vainio's (1995) comparison of hedonic pricing and CV, the questionnaire was sent three years after the transaction, by which time the buyer had perceived the full extent of a disturbance effect from the noise of a nearby motorway. In this case the hedonic models underestimated the effect.

Gartner and Chappelle (1996) noted that in situations where a property possessing certain attributes is not frequently traded at an open market, the owners' own estimates of value provide more useful estimates of economic benefits than those derived from sales transactions. Ready and colleagues (1997) asserted that when non-use values (e.g., altruism toward current residents and preservation of cultural heritage) are large, contingency valuation may be preferred to hedonic methods (see also Magat et al., 2000). The main weaknesses of conventional survey tools are (1) the possibility to manipulate the outcome by predetermining the nature of response mode; (2) they are incapable of accommodating explicitly the multi-attribute nature of trade-offs between alternative choices. We might need very contextsensitive insight into how various multi-dimensional values are being perceived by the individual. Then, a pure competitive market approach loses validity.

The multi-attribute value tree (MAVT; in Anglo-American literature often 'utility tree') provides a formal way of thinking through multi-dimensional eliciting of peoples' weighted objectives in the context of their expressed values and selected project alternatives (e.g., Gregory et al., 1997). Tools such as the MAVT are suitable for evaluation of other than monetary values when they are mixed with or linked with monetary ones (e.g., Miettinen and Hämäläinen, 1996). This approach includes techniques such as the analytic hierarchy process (AHP), the self-explicated utility method and conjoint analysis. The first two are hierarchical models and thus apply the value tree concept, whereas the last one is based on choice profiles. All three are aimed at making choices according to preferences in a multi-attribute problem 
setting, in contrast to the purely economic WTP setting of revealed preferences and CV (e.g., Miettinen and Hämäläinen, 1996; Pöyhönen, 1998). All of these techniques contain an assumption about the deterministic preferences of the interviewed subjects. In the built environment context, they could be understood as different perceptions of experts from a flexible, problem-specific point of view (e.g., Nevalainen et al., 1990; Laakso et al., 1995).

In these methods the weighting of the preferences becomes a question of elicitation (Pöyhönen, 1998; Ruokolainen and Tempelmans Plat, 1998). The AHP uses a pairwise matrix comparison of preferences, especially when no price information is available. The AHP has been applied in several ways within this particular research area. Like Kauko (2002), Fischer (2003) too sees a more qualitative approach as an improvement, the difference between these two specific methods being that Fischer also mixes price criteria with the other criteria already in the model structure, whereas Kauko arrives at a pure quality rank - possibly to compare with actual prices at a later stage. Fischer (2003), like Kauko (2002), concludes that the problem for this approach, if it is being adopted for practical applications, may be the very low time- and cost-efficiency. Ghyoot (2001) uses the AHP for site selection, together with the repertory grid (RG) - a more qualitative method, the aim of which is to assist in finding the best choice on the basis of in-depth interviews. The combination of weighted attributes obtained could also be used to construct a quality-constant geo-index included in the hedonic model (see Laakso et al., 1995; Bender et al., 1997, 1999; Din et al., 2001). With a quality model based on pairwise comparisons with the AHP, one can compare the elicitation of different interest groups for different type of areas or houses (e.g., Nevalainen et al., 1990; see also Ruokolainen and Tempelmans Plat, 1998; Pöyhönen, 1998; Gregory, 2000). Yet another strand of the behavioural real estate literature is inspired by the seminal work of psychologists Tversky and Kahneman on heuristic problem solving (see Goodman and Ittner, 1992; Adair et al., 1996; Diaz, 1998; Daly et al., 2003).

\section{Comparison of methods}

Based on our reading of the literature, it seems evident that value modelling is a growing field. Despite the lack of consensus with regard to a single, dominant framework, the great opportunities offered by computer-assisted mass appraisal allow researchers to apply innovative procedures. These may be grouped into the following five areas:

- Strict quantitative method based on parametric hedonic regression (or more generally, economic equilibrium) models - either with or without an explicitly spatial extension. 
- Flexible (non-/semi-parametric) quantitative methods; these are still formally accommodated within mainstream economic modelling.

- Flexible quantitative method based on machine learning; these are 'intelligent' (i.e., machine learning) methods from the computer science discipline.

- Rule-based expert systems of valuation, using either transaction price or expert interviews data; may be based on machine learning.

- Methods, where interviews and surveys such as multi-criteria decision methods replace market data calculation; usually both quantitative in the sense that they are mathematical, and qualitative in the sense that they use judgmental data. These stated choice/preferences methods serve a purpose in certain well-specified problem settings.

We highlight the following criteria (in descending order) to establish a protocol:

1 Accuracy of independent valuations (see e.g., Thibodeau, 2003);

2 Conceptual soundness;

3 Analysis of valuation variation where more than one mass appraisal methodology is applied (Brown et al., 1998);

4 Internal consistency of the model;

5 Nature of the adjustment. Is the adjustment of the model predominantly spatial/structural or temporal in nature? (Only in the latter case a smooth, linear model is valid);

6 Reliability and robustness of the model (i.e., sensitivity of result to external alterations in input parameters);

7 Feasibility (i.e., cost- and time-efficiency).

To give some examples, the multi-attribute approach is steadily gaining support. It seems flexible and is promising. Arguably, allowing for (consumer) behaviour and quality improves the conceptual soundness of the value model (as suggested by Daly et al., 2003); therefore, MAVT probably is the most conceptually sound approach to valuation as it explicitly deals with such elements. It is, however, difficult to imagine a possible application of these works to mass appraisal. Besides, there are uncertainties yet to be solved when applying methods based on hypothetical data. The obvious one is the feasibility of the study and its cost. However, the most important concern is how to perform an objective comparison between estimates based on market data and those based on hypothetical values.

For the spatial aspect, the interview-based methods discussed above come in particularly handy, as environmental information is not easy to record (see e.g., Langdon, 1978). However, the preferences and choices are evoked under hypothetical conditions that do not necessarily represent the actual 
choices made in the real world. Also temporal and spatial stability is hard to incorporate in these methods.

As each approach has its limits, the question is always about what particular aspect needs to be reflected upon. Is it accuracy, feasibility or some non-technical aspect that may require more thorough analysis, such as the adjustment structure? We may find that, regardless of criteria used, the MRA does remain a credible method. Finally, we introduce two more 'institutional criteria' in the application of mass appraisal methodology: one, suitability to the property market context; two, path-dependence - thus, is the institutional practice favourable to introducing new tools? In developing countries and emerging economies particularly, data quality is the main problem to overcome. For example, Pacharavanich and Rossini (2001) conclude that there is little point in developing the methodology if the data in general and the transaction prices in particular, are not good (cf. Kryvobokov, 2004).

\section{Summary and conclusions}

When reviewing the set of mass appraisal methods, the criteria are partly methodological and partly institutional. Not only do we put forward claims about what constitutes an adequate and appropriate method, but also those about the suitability of the method for the institutional context of use.

The most common methodological framework for mass appraisal is the hedonic regression model, which recently has been extended into various flexible and spatial regression models. This tradition may be divided into two main types: parametric and flexible (i.e., semi- and non-parametric) methods. The parametric variant is more efficient but prone to high specification error. This type is model-driven, which means that in-sample estimation is sufficient to determine the accuracy (but see Fletcher et al., 2003, who suggest that, even in parametric regression, out-of-sample testing is required). The flexible variant is inefficient but has a low specification error. This method is data-driven, which means that out-of-sample testing is necessary to evaluate its performance.

Interview-based methods merely deal with hypothetical data, and generate only hypothetical results about property value (which, paradoxically, is a hypothetical concept). If no good market data exist this approach becomes crucial to obtaining any results. Also, if market data are considered invalid for the specific appraisal task, in particular if we need to ascertain the behavioural nuances involved, this category of tools become relevant.

Finally, the institutional dimensions should not be overlooked. Correlating the valuation method with the market context may prove explanatory when considering differing results achieved from different times or places. 
For example, a small or middle-sized city typically has less location factors influencing prices, and a more general functional relationship between such influences and the price, than a big city where price influences are of several kinds, and often intangible and interrelated. Thus, there would be added value with a more complex model in the case of a larger city only.

When looking at the current trends of valuation modelling research, a likely scenario would be that price research is moving towards spatial tools on the one hand, and on the other towards pragmatic tools. Perhaps there is also a turn to more qualitative methods, but that depends on whether a qualitative method can be adapted cost-efficiently. Here, two different arguments about how to advance the field can be forwarded:

- Following the orthodox view: to remain within equilibrium modelling and sophisticated econometric techniques in order to keep up with the academic tradition.

- Following a more heretic/heterodox view: to only consider the practical aspects of accuracy and feasibility; then, we can look beyond hedonic modelling extensions towards computer simulation, artificial intelligence and machine-learning paradigms; the best result we get when combining two or more techniques.

One crucial requirement within the mass appraisal pertains to incorporating the influence of the location into the model. A further issue is whether we need automation, which has to do with the cost-savings and benefits generated by economics of scale.

The arguments discussed may be summarized into three crucial aspects, each of which poses potential problems for the estimation of value:

1 The technical aspect: variables, transformations etc. - this is traditional valuation territory.

2 The institutional aspect: market efficiency, data availability - this is an area yet to be explored on both sides of 'the pond'.

3 How to adapt further data collection to progress or degradation in the surrounding environment or to new standards of application? This issue is about capturing unknown influences and about robustness in relation to the model/criteria of the system of valuation.

The following respective chapters deal with mass appraisal practice (Chapters 2-5), orthodox methods (Chapters 6-8), heretic methods (Chapters 9-11), comparison of tools using a set of specific criteria (Chapters 12-14), and conclusions (Chapter 14). Note that the contributors will deal with residential property only. This is, however, not a predefined choice, but mainly due to practical reasons: the other property types (land, 
commercial real estate etc.) have been targeted much less in research. The reasons for the relative deficit in such studies is, first, that data is scarce due to the heterogeneity of sales; second, that most of this research applies a macro-economic perspective that is incompatible with the residential localization and hedonic perspectives applicable to house price analysis; and third, for these properties the valuation methods most commonly used are based in rent capitalization - not comparable sales or regressions.

\section{References}

Adair, A.S., Berry, J.N. and McGreal, S. (1996) Valuation of Residential Property: Analysis of Participant Behaviour. Journal of Property Valuation and Investment, 14(1): 20-35.

Bagnoli, C. and Smith, H. (1998) The Theory of Fuzzy Logic and its Application to Real Estate Valuation. Journal of Real Estate Research, 16: 169-199.

Ball, M.J. (1973) Recent Empirical Work on the Determinants of Relative House Prices. Urban Studies, 10: 213-233.

Bender, A., Din, A., Favarger, P., Hoesli, M. and Laakso, J. (1997) An Analysis of Perceptions Concerning the Environmental Quality of Housing in Geneva. Urban Studies, 34(3): 503-513.

Bender, A., Din, A., Hoesli, M. and Laakso, J. (1999) Environmental Quality Perceptions of Urban Commercial Real Estate. Journal of Property Investment and Finance, 17(3): 280-296.

Bible, D.S. and Hsieh, C.-H. (1996) Applications of Geographic Information Systems for the Analysis of Apartment Rents. Journal of Real Estate Research, 12(1): 79-88.

Bökemann, D. and Feilmayr, W. (1997) Differences among Social Groups in their Willingness to Pay for Distinct Real Estate Properties. Conference Paper. American Real Estate and Urban Economics Association 6th International Conference, Berkeley, May 31-June 2.

Bolen, F., Yirmibesoglu, F., Turkoglu, H. and Korca, P. (1999) Determinants of Land Prices in Istanbul: A Case Study. ERSA99, 39th European Congress, Dublin, Ireland, 23-27 August. CD-Rom by Forfás.

Bonissone, P.P., Cheetam, W., Golibersuch, D. and Khedkar, P. (1998) Automated Residential Property Valuation: An Accurate and Reliable Approach Based on Soft Computing. In: Ribeiro R., Zimmermann H., Yager R.R. and Kacprzyk J. (eds), Soft Computing in Financial Engineering. Heidelberg: Physica-Verlag.

Borst, R. (1995) Artificial Neural Networks in Mass Appraisal. Journal of Property Tax Assessment and Administration, 1: 5-15.

Breffle, W.S., Morey, E.R. and Lodder, T.S. (1998) Using Contingent Valuation to Estimate a Neighbourhoods Willingness to Pay to Preserve Undeveloped Urban Land. Urban Studies, 35(4): 715-727.

Brown, G.R., Matysiak, G.A. and Shepherd, M. (1998) Valuation Uncertainty and the Mallinson Report. Journal of Property Research, 15(1): 1-13.

Chica-Olmo, J. (2007) Prediction of Housing Location Price by a Multivariate Spatial Method: Cokriging. The Journal of Real Estate Research, 29(1): 91-114.

Coleman, J.W. and Larsen, J.E. (1991) Alternative Estimation Techniques for Linear Appraisal Models. The Appraisal Journal, LIX(4): 526-532. 
Colwell, P.F. (1998) A Primer on Piecewise Parabolic Multiple Regression Analysis via Estimations of Chicago CBD Land Prices. Journal of Real Estate Finance and Economics, 17(1): 87-97.

Colwell, P.F. and Munneke, H.J. (2003) Estimating a Price Surface for Vacant Land in an Urban Area. Land Economics, 79(1): 87-97.

Cooley, R.E., Pack, A.D., Hobbs, M. and Clewer, A.D.E. (1994) A Genetic Algorithm for Modelling Locational Effects on Residential Property Prices. 'The Cutting Edge 1994' Conference Proceedings, 179-193.

Daly, J., Gronow, S., Jenkins, D. and Plimmer, F. (2003) Consumer Behaviour in the Valuation of Residential Property: A Comparative Study in the UK, Ireland and Australia. Property Management, 21(5): 295-314.

d'Amato, M. (2002) Appraising Property with Rough Set Theory. Journal of Property Investment and Finance, 20(4): 406-418.

d'Amato, M. (2003) Using Valued Tolerance Decision Rules for Property Valuation with Rough Set Theory. 10th ERES Conference, Helsinki, Finland, 10-13 June.

d'Amato, M. (2007) Comparing Rough Set Theory with Multiple Regression Analysis as Automated Valuation Methodologies. International Real Estate Review, 10(2): 42-65.

d'Amato, M. and Siniak, N. (2003) An Application of Fuzzy Numbers for Property Investment and Valuation. International Journal of Strategic Property Management, 7(3): $129-143$

de Soto, H. (2000) The Mystery of Capital: Why Capitalism Triumphs in the West and Fails Everywhere Else. New York: Basic Books.

Diaz, J. III (1998) The First Decade of Behavioral Research in the Discipline of Property. 'The Cutting Edge 1998' Conference Proceedings, ISBN 0-85406-922-4.

Din, A., Hoesli, M. and Bender, A. (2001) Environmental Variables and Real Estate Prices. Urban Studies, 38(11): 1989-2000.

Ding, C., Simons, R. and Baku, E. (2000) The Effect of Residential Investment on Nearby Property Values: Evidence from Cleveland, Ohio. Journal of Real Estate Research, 19(1/2): 23-48.

Dubin, R.A. and Sung, C.-H. (1987) Spatial Variation in the Price of Housing: Rent Gradients in Non-Monocentric Cities. Urban Studies, 24: 193-204.

Federal Land Cadastre of Russia (2001) Land (Real estate) Mass Valuation Systems for Taxation Purposes in Europe. UN ECE Working Party on Land Administration, November.

Feenberg, D. and Mills, E.S. (1980) Measuring the Benefits of Water Pollution Abatement. Studies in Urban Economics. New York: Academic Press.

Fischer, D. (2003) Multi-Criteria Analysis of Ranking Preferences on Residential Traits. 10th ERES Conference, Helsinki, Finland, 10-13 June.

Fletcher, M., Mangan, J. and Raeburn, E. (2003) Comparing Hedonic Models for Estimating and Forecasting House Prices. Property Management, 22(3): 189-200.

Francke, M.K. and Vos, G.A. (2004) The Hierarchical Trend Model for Property Valuation and Local Price Indices. Journal of Real Estate Finance and Economics, 28: 179-208.

Gartner, W.C. and Chappelle, D.E. (1996) The Influence of Natural Resource Characteristics on Property Value: A Case Study. Journal of Travel Research, 35(1): 64-71.

Gatzlaff, D.H. and Haurin, D.R. (1997) Sample Selection Bias and Repeat-Sales Index Estimates. Journal of Real Estate Finance and Economics, 14(1/2): 33-50. 
Geoghegan, J., Wainger, L.A. and Bockstael, N.E. (1997) Spatial Landscape Indices in a Hedonic Framework: An Ecological Economics Analysis Using GIS. Ecological Economics, 23: 251-264.

Ghyoot, V.K. (2001) Using Management Science in Site Selection: A Case Study in Office Site Selection for a Regional Authority in South Africa. 3rd AFRES/TIVEA/RICS Foundation Conference, Arusha, Tanzania, October.

Gillen, K., Thibodeau, T. and Wachter, S. (2001) Anisotropic Autocorrelation in House Prices. Journal of Real Estate Finance and Economics, 23(1): 5-30.

Gonzalez, A.J. and Laureano-Ortiz, R. (1992) A Case-Based Reasoning Approach to Real Estate Property Appraisal. Expert Systems with Application, 4: 229-246.

González, M.A.S., Soibelman, L. and Formoso, C.T. (2002a) A New Approach to Spatial Analysis in CAMA. 9th European Real Estate Society Conference (ERES), Glasgow, UK.

González, M.A.S., Soibelman, L. and Formoso, C.T. (2002b) Explaining Results in a Neural-Mass Appraisal Model. 9th European Real Estate Society Conference (ERES), Glasgow, UK.

González, M.A.S., Soibelman, L. and Formoso, C.T. (2005) A New Approach to Spatial Analysis in CAMA. Property Management, 23(5): 312-327.

Goodman, J.L. Jr and Ittner, J.B. (1992) The Accuracy of Home Owners' Estimates of House Value. Journal of Housing Economics, 2: 339-357.

Gregory, R. (2000) Valuing Environmental Policy Options: A Case Study Comparison of Multiattribute and Contingent Valuation Survey Methods. Land Economics, 76(2): 151-173.

Gregory, R., Flynn, J., Johnson, S.M., Satterfield, T.A., Slovic, P. and Wagner, R. (1997) Decision-Pathway Surveys: A Tool for Resource Managers. Land Economics, 73(2): 240-254.

Harvey, J. (1996) Urban Land Economics: The Economics of Real Property Markets, London: Macmillan.

Hoesli, M., Giacotto, C. and Favarger, P. (1997a) Three New Real Estate Price Indices for Geneva, Switzerland. Journal of Real Estate Finance and Economics, 15(1): 93-109.

Hoesli, M., Thion, B. and Watkins, C. (1997b) A Hedonic Investigation of the Rental Value of Apartments in Central Bordeaux. Journal of Property Research, 14: 15-26.

International Valuation Standards (2005) International Valuation Standards, 7th edn. www.ivsc.org. Last accessed on 26 February 2008.

Jenkins, D.H., Lewis, O.M., Almond, N., Gronow, S.A. and Ware, J.A. (1999) Towards an Intelligent Residential Appraisal Model. Journal of Property Research, 16(1): 67-90.

Kang, H.-B. and Reichert, A.K. (1991) An Empirical Analysis of Hedonic Regression and Grid-Adjustment Techniques in Real Estate Appraisal. AREUEA Journal, 19(1): 70-91.

Kauko, T. (2002) Modelling Location in House Prices - Neural Network and Value Tree Approaches, PhD Thesis. Utrecht.

Kauko, T. and Peltomaa, H. (1998) A Comparison Between Neural Network and Multiple Regression Approaches: Effects of Transmission Line on Residential Property Values. Surveying Science in Finland, 16(1/2): 52-87.

Knight, J.R., Hill, R.C. and Sirmans, C.F. (1993) Stein Rule Estimation in Real Estate Appraisal. The Appraisal Journal, October, 539-544.

Kryvobokov, M. (2004) Urban Land Zoning for Taxation Purposes in Ukraine. Property Management, 22(3): 214-229. 
Kyllönen, L. and Räty, T. (2000) Asuntojen hinta-laatusuhde Joensuussa, semiparametrinen estimointi (in Finnish). VATT-tutkimuksia, 67: 53 pgs.

Laakso, J., Bender, A., Din, A., Favarger, P. and Hoesli, M. (1995) An Analysis of Perceptions Concerning the Evironmental Quality of Residential Real Estate in Geneva, 1st IRES Conference, Stockholm 28 June-1 July.

Laakso, S. (1997) Urban Housing Prices and the Demand for Housing Characteristics, The Research Institute of the Finnish Economy (ETLA) A 27, Helsinki.

Lake, I.R., Lovett, A.A., Bateman, I.J. and Langford, I.H. (1998) Modelling Environmental Influences on Property Prices in an Urban Environment. Computers, Environment and Urban Systems, 22(2): 121-136.

Langdon, F.J. (1978) Monetary Evaluation of Nuisance from Road-Traffic Noise: An Exploratory Study. Environment and Planning A, 10: 1015-1034.

Lee, Y.-L., Yeh, K.-Y. and Hsu, K.-C. (2003) Fair Evaluation of Real Estate Value in Urban Area Via Fuzzy Theory. 10th ERES Conference, Helsinki, Finland, 10-13 June.

Lentz, G.H. and Wang, K. (1998) Residential Appraisal and the Lending Process: A Survey of Issues. Journal of Real Estate Research, 15(1/2): 11-39.

McCluskey, W.J. and Anand, S. (1999) The Application of Intelligent Hybrid Techniques for the Mass Appraisal of Residential Properties. Journal of Property Investment and Finance, 17(3): 218-238.

McCluskey, W., Deddis, W., McBurney, R.D., Mannis, A. and Borst, R. (1997) Interactive Application of Computer Assisted Mass Appraisal and Geographic Information Systems. Journal of Property Valuation and Investment, 15: 448-465.

McGreal, S., Adair, A., McBurney, D. and Patterson, D. (1998) Neural Networks: The Prediction of Residential Values. Journal of Property Valuation and Investment, 16(1): 57-70.

Magat, W., Huber, J. and Viscusi, W.K. (2000) An Iterative Choice Approach to Valuing Clean Lakes, Rivers, and Streams. Journal of Risk and Uncertainty, 21(1): 7-43.

Mansfield, J.R. and Lorenz, D.P. (2004) Shaping the Future the Impacts of Evolving International Accounting Standards on Valuation Practice in the UK and Germany. Journal of Property Investment and Finance, 22(4): 289-303.

Mason, C. and Quigley, J.M. (1996) Non-Parametric Hedonic Housing Prices. Housing Studies, 11(3): 373-385.

Meese, R. and Wallace, N. (1991) Nonparametric Estimation of Dynamic Hedonic Price Models and the Construction of Residential Housing Price Indices. AREUEA Journal, 19(3): 308-332.

Michaels, R.G. and Smith, V.K. (1990) Market Segmentation and Valuing Amenities with Hedonic Models: The Case of Hazardous Waste Sites. Journal of Urban Economics, 28(2): 223-242.

Miettinen, P. and Hämäläinen, R.P. (1996) Ympäristön arvottaminen - Taloustieteelliset ja monitavoitteiset menetelmät (in Finnish). Helsinki University of Technology, Systems Analysis Laboratory B19, Espoo.

Miller, N.G. (1982) Residential Property Hedonic Pricing Models: A Review. In: Sirmans C.F. (ed.), Urban Housing Markets and Property Valuation. Research in Real Estate, Vol. 2, Jai Press Inc., Greenwich, CT, pp. 31-56.

Needham, B., Franke, M. and Bosma, P. (1998) How the City of Amsterdam is Using Econometric Modelling to Value Real Estate. Journal of Property Tax Assessment and Administration, 3(2): 25-46. 
Nevalainen, R., Staffans, A. and Vuorela, P. (1990) Asumisen laadun arviointi ja tutkiminen. (Evaluating and studying the quality of housing (in Finnish.) YTK B 60, Helsinki.

Nguyen, N. and Cripps, A. (2001) Predicting Housing Value: A Comparison of Multiple Regression Analysis and Artificial Neural Networks. Journal of Real Estate Research, 22(3): 313-336.

Orford, S. (1999) Valuing the Built Environment - GIS and House Price Analysis. UK: Ashgate, pp. 216.

Orford, S. (2002) Valuing Locational Externalities: A GIS and Multilevel Modelling Approach. Environment and Planning B: Planning and Design, 29: 105-127.

O'Roarty, B., McGreal, S., Adair, A. and Patterson, D. (1997) Case-Based Reasoning and Retail Rent Determination. Journal of Property Research, 14(4): 309-328.

Pace, R.K. (1995) Parametric, Semiparametric, and Nonparametric Estimation of Characteristic Values Within Mass Assessment and Hedonic Pricing Models. Journal of Real Estate Finance and Economics, 11: 195-217.

Pacharavanich, P., and Rossini, P. (2001) Examining the Potential for the Development of Computerised Mass Appraisal in Thailand. Pacific-Rim Real Estate Society (PRRES) Conference, Adelaide, 21-24 January.

Pacharavanich, P., Wongpinunwatana, N. and Rossini, P. (2000) The Development of a Case-Based Reasoning System as a Tool for Residential Valuation in Bangkok. PacificRim Real Estate Society (PRRES) Conference, Sydney, 23-27 January.

Páez, A., Uchida, T. and Miyamoto, K. (2002) A General Framework for Estimation and Inference of Geographically Weighted Regression Models: 1. Location-Specific Kernel Bandwidths and a Test for Locational Heterogeneity. Environment and Planning A, 34: 733-754.

Pagourtzi, E. and Assimakopoulos, V. (2003) Development of Real Estate Evaluation System with the Use of G.I.S. Technology. 10th ERES conference, Helsinki, Finland, 10-13 June.

Pavlov, A.D. (2000) Space-Varying Regression Coefficients: A Semi-Parametric Approach Applied to Real Estate Markets. Real Estate Economics, 28(2): 249-283.

Pöyhönen, M. (1998) On Attribute Weighting in Value Trees. Helsinki University of Technology, Systems Analysis Laboratory A73, Espoo.

Ready, R.C., Berger, M.C. and Blomquist, G.C. (1997) Measuring Amenity Benefits from Farmland: Hedonic Pricing vs. Contingent Valuation. Growth and Change, 28(4): 438-458.

Riddel, M. (2001) A Dynamic Approach to Estimating Hedonic Prices for Environmental Goods: An Application to Open Space Purchase. Land Economics, 77(4): 494-512.

Robinson, R. (1979) Housing Economics and Public Policy. London: MacMillan.

Rodriguez, M., Sirmans, C.F. and Marks, A. (1995) Using Geographic Information Systems to Improve Real Estate Analysis. Journal of Real Estate Research, 10(2): 163-173.

Rothenberg, J., Galster, G., Butler, R. and Pitkin, J. (1991) The Maze of Urban Housing Markets: Theory, Evidence and Policy. Chicago: University of Chicago Press.

Ruokolainen, A. (1999) A Decision Support System for Investing in Owner-Occupied Dwellings. Tampere University of Technology, Publications 256. Tampere.

Ruokolainen, A. and Tempelmans Plat, H. (1998) A System for Optimizing Private House Owner's Spendings and Benefits. Conference paper. 4th Design and Decision Support Systems in Architecture and Urban Planning Conference, Maastricht, The Netherlands, 26-29 July. 
Salvo, F. (1999) I Segmenti del Mercato Immobiliare e le Microzone Censuarie (in Italian). Rivista del Dipartimento del Territorio, 3: 101-114.

Scott, I. and Gronow, S. (1990) Valuation Expertise: Its Nature and Application. Journal of Valuation, 8(4): 362-375.

Simonotti, M. (1998), La Segmentazione del Mercato Iimmobiliare per la Stima degli Immobili Urbani (in Italian). XXVIII Ce.S.E.T. Meeting Valori immobiliari Catasto e Fiscalità, Rome.

Soibelman, L. and González, M.A.S. (2002) A Knowledge Discovery in Databases Framework for Property Valuation. Journal of Property Tax Assessment and Administration, 7(2): 77-106.

Sui, D.Z. (1992) A Fuzzy GIS Modelling Approach for Urban Land Evaluation. Computers, Environment and Urban Systems, 16: 101-115.

Tay, D.P.H. and Ho, D.K.K. (1992) Artificial Intelligence and the Mass Appraisal of Residential Apartments. Journal of Property Valuation and Investment, 10(2): 525-540.

Thériault, M., Des Rosers, F. and Joerin, F. (2005) Modelling Accessibility to Urban Services Using Fuzzy Logic. A Comparative Analysis of Two Methods. Journal of Property Investment $\Theta$ Finance, 23(1): 22-54.

Thibodeau, T.G. (2003) Marking Single-Family Property Values to Market. Real Estate Economics, 31(1): 1-22.

Vainio, M. (1995) Liikenteen melu ja ilmansaasteet: Ulkoisvaikutusten arvo hedonisten hintojen ja contingent valuation -menetelmillä (in Finnish). Kansantaloudellinen Aikakauskiria, 91(2): 240-244.

Verkooijen, W.J.H. (1996) Neural Networks in Economic Modelling. Doctoral dissertation, Tilburg University, Center for Economic Research, 205 pp.

White, H. (1989) Learning in Artificial Neural Networks: A Statistical Perspective. Neural Computation, 1: 425-464.

Wilhelmsson, M. (2000) Traffic Noise and Property Values. Royal Institute of Technology, Department of Real Estate and Construction Management, Memorandum 5:50. Stockholm.

Wilhelmsson, M. (2002) Spatial Models in Real Estate Economics. Housing, Theory and Society, 19: 92-101.

Willis, K.G. and Garrod, G.D. (1993) Not from Experience: A Comparison of Experts' Opinions and Hedonic Price Estimates of the Incremental Value of Property Attributable to an Environmental Feature. Journal of Property Research, 10: 193-216.

Worzala, E., Lenk, M. and Silva, A. (1995) An Exploration of Neural Networks and its Application to Real Estate Valuation. Journal of Real Estate Research, 10(2): 185-201.

Wyatt, P. (1995) A Spatial Analysis of Property Values. 'The Cutting Edge 1995' Conference Proceedings, Volume Two, pp. 21-33.

Wyatt, P. (1996a) The Development of a Property Information System for Valuation Using a Geographical Information System (GIS). Journal of Property Research, 13: 317-336.

Wyatt, P. (1996b) Using a Geographical Information System for Property Valuation. Journal of Property Valuation and Investment, 14(1): 67-79.

Wyatt, P.J. (1997) The Development of a Gis-Based Property Information System for Real Estate Valuation. International Journal of Geographical Information Science, 11(5): 435-450.

Wyatt, P. (1999) Senior Lecturer, University of the South of England, Discussion, 10 September, London. 